\title{
EFETIVAÇÃO DE PRECEITOS CONSTITUCIONAIS EM AMBIENTE PRISIONAL
}

\author{
EFFECTIVENESS OF CONSTITUTIONAL PRECEPTS IN A PRISON \\ ENVIRONMENT
}

\author{
Aline Andressa Trennepohl Borges ${ }^{1}$ \\ Bruno da Silva Nascimento Soares ${ }^{2}$ \\ Gislaine Silveira Nunes ${ }^{3}$ \\ Suelen da Rosa Teixeira ${ }^{4}$ \\ Tiago dos Santos Arãos \\ Fabio Rafael Corrêa Oliveira ${ }^{6}$
}

RESUMO: O sistema prisional brasileiro, tem como característica marcante a precariedade das unidades penitenciárias, sendo que a ausência de condições sanitárias, superlotação e completo desrespeito aos direitos humanos e preceitos constitucionais são rotineiros. Diante deste complexo cenário, o estudo tem como objetivo analisar de quais modos os direitos fundamentais da população carcerária são violados, sendo que os objetivos específicos consistem em: caracterizar os chamados direitos fundamentais sob à luz da Constituição, analisar por quais motivos o sistema carcerário brasileiro vem sendo negligência pelo Estado, assim como estudar a importância da efetivação destes direitos como forma de reabilitação social dos detentos. O estudo se justifica a partir da ótica de que a Constituição enfatiza a igualdade de direitos entre os cidadãos brasileiros, assim como determina que é dever do Estado punir, mas também de criar condições para a reabilitação da população carcerária, sendo que a punição deve se concentrar na privação de liberdade e jamais em exposição dos mesmos a situações degradantes dentro das penitenciárias. Estabelecidos estes preceitos, o estudo busca alcançar os objetivos através de uma revisão de literatura de caráter qualitativo.

\footnotetext{
I Graduada em Ciências Contábeis pela Universidade de Passo Fundo(UPF). Pós-graduada em Segurança Pública pela Faculdade Alfamérica. Policial Penal da SEAPEN/RS. E-mail: aline_atb@hotmail.com.

${ }^{2}$ Graduado em Administração pelo Centro Universitário Metodista (IPA). Pós-graduado em Gestão Prisional pela Faveni. Policial Penal da SEAPEN/RS. E-mail: Bruno.nascimento.adm@gmail.com.

${ }^{3}$ Graduada em Comunicação Social- Habilitada em Relações Públicas pela Universidade Federal do Rio Grande do Sul (UFRGS). Pós-graduada em Perfis criminais e comportamentais pela IBRA. Policial Penal da SEAPEN/RS. E-mail:gislainesilveirar6@gmail.com.

4 Graduada em Gestão Ambiental pela Universidade da Região da Campanha( URCAMP). Pósgraduada em Perícia e Auditoria Ambiental pela Uninter. Pós-graduada em Segurança Pública e Cidadania pela IBRA. Policial Penal da SEAPEN/RS. E-mail:suelen.teixeira@hotmail.com.

5 Formado em Letras pela UFPel-RS; Especialista em Inteligência Policial, Segurança Pública e Direitos Humanos. Policial Penal do Estado do Rio Grande do Sul (SUSEPE - RS).E-mail: tiagoarao@susepe.rs.gov.br.

${ }^{6}$ Graduado em Gestão Pública pela Faculdade Cruzeiro do Sul. MBA em gestão Pública pela Faculdade Cruzeiro do Sul. Policial Penal SEAPEN/RS.E-mail: rafael.oliveira.msn@hotmail.com.
} 
Palavras-chave: Constituição. Ambiente prisional. Direitos fundamentais.

ABSTRACT: The Brazilian prison system is characterized by the precarious nature of penitentiary units, and the absence of sanitary conditions, overcrowding and complete disrespect for human rights and constitutional precepts are routine. In view of this complex scenario, the study aims to analyze how the fundamental rights of the prison population are violated, and the specific objectives are to: characterize the socalled fundamental rights in the light of the Constitution, analyze why the Brazilian prison system it has been negligence by the State, as well as studying the importance of realizing these rights as a form of social rehabilitation for detainees. The study is justified from the point of view that the Constitution emphasizes equal rights among Brazilian citizens, as well as determines that it is the State's duty to punish, but also to create conditions for the rehabilitation of the prison population, and the punishment must be concentrate on deprivation of liberty and never on exposure of them to degrading situations within the penitentiaries. Having established these precepts, the study seeks to achieve the objectives through a qualitative literature review.

Keywords: Constitution; Prison environment; Fundamental rights.

\section{INTRODUÇÃO}

A Constituição brasileira de 1988, estabelece que todos os cidadãos do país têm direitos e deveres, que devem ser assegurados em quaisquer circunstâncias, sem distinção de cor, raça, sexo, ideologias ou condições econômicas e sociais. Contudo, na prática, não se vê essas garantias sendo efetivadas, especialmente em relação a população carcerária.

As unidades prisionais brasileiras, tem como característica marcante a ausência de elementos básicos para a instalação de detentos, a falta de condições sanitárias, a superlotação, assim como a disseminação de doenças é comum, o que impacta negativamente qualquer estratégia destinada a restauração destes presos, para uma futura reinserção em sociedade. Ou seja, todos esses fatores escancaram um complexo cenário de ineficiência do poder público em prover condições de ressocialização, assim como fere diretamente os direitos humanos e demais prerrogativas contidas na Constituição.

Diante deste complexo cenário, o estudo tem como objetivo analisar de quais modos os direitos fundamentais da população carcerária são violados, sendo que os objetivos específicos consistem em: caracterizar os chamados direitos fundamentais sob à luz da Constituição, analisar por quais motivos o sistema carcerário brasileiro 
vem sendo negligência pelo Estado, assim como estudar a importância da efetivação destes direitos como forma de reabilitação social dos detentos.

Com os objetivos do estudo definido, se levantou o seguinte problema de pesquisa: as condições degradantes as quais a população carcerária é exposta, é fator determinante para os elevados índices de reincidência criminal no Brasil?

O estudo se justifica também a partir desta ótica, haja vista que a Constituição enfatiza a igualdade de direitos entre os cidadãos brasileiros, assim como determina que é dever do Estado punir, mas também de criar condições para a reabilitação da população carcerária, sendo que a punição deve se concentrar na privação de liberdade e jamais em exposição dos mesmos a situações degradantes dentro das penitenciárias.

O encaminhamento metodológico do estudo, se trata de uma revisão de literatura de caráter qualitativo, em pesquisas que tiveram como enfoque, a discussão acerca dos preceitos constitucionais relacionados a dignidade da pessoa humana, especialmente daqueles que cumprem uma pena dentro de unidades de encarceramento no país, assim como de estudos relacionados a importâncias das estratégias de ressocialização e que trazem uma reflexão a respeito do papel do Estado e da comunidade de uma forma geral, em tornar essa conjuntura menos degradante, e com maior capacidade de reabilitar e reinserir em sociedade essa população carcerária.

Sendo assim, o estudo traz inicialmente uma discussão e caracterização dos chamados direitos fundamentais à luz da Constituição, assim como apontando as obrigações do Estado. Em seguida, mostra um panorama atual das penitenciárias brasileiras, ressaltando as condições precárias das mesmas, por fim, discute a relevância de estratégias voltadas a mitigar esse complexo cenário, com ações tanto do poder público, quanto de conscientização da opinião pública, tudo com o intuito de promover uma sociedade mais justa e igualitária.

\section{DIREITOS FUNDAMENTAIS À LUZ DA CONSTITUIÇÃO}

A Constituição brasileira que foi promulgada no ano de 1988 , tem como premissa a igualdade e o respeito aos cidadãos, sendo que determinadas prerrogativas são consideradas basilares e inegáveis a qualquer indivíduo, independentemente de suas condições sociais, ideologias, crenças ou raça, sexo e religião. Estes são tidos como 
os direitos fundamentais, que se referem ao acesso a tratamentos de saúde sem custos, de educação, segurança, moradia, assim como o respeito a sua dignidade (SILVA, 2012)

Ou seja, a dignidade se mostra como elemento norteador da Constituição, haja vista que a não efetivação de qualquer direito fundamental, fere a dignidade da pessoa humana, além de ser incorreto à luz da carta magna. Embora tais preceitos estejam expressos na Constituição e devam ser garantidos pelo Estado e pela comu nidade, isso não ocorre na prática em algumas situações, um exemplo claro disto, é o tratamento que detentos recebem ao ingressarem em uma unidade penitenciária, como exposto:

\begin{abstract}
Assim, surge a temática proposta da dignidade da pessoa humana, princípio constitucional e fundamento da República, e que, portanto, norteia toda a Constituição, a legislação infraconstitucional, o comportamento da sociedade e a conduta do Estado. Passados 25 anos da promulgação da Constituição Federal de 1988, o princípio da dignidade da pessoa humana continua a ser desrespeitado, havendo contradição entre o texto constitucional e a realidade concreta. Basta olhar para as condições em que se encontra o atual sistema prisional brasileiro, para perceber que a barbárie continua e que a pessoa humana é esquecida e violada quando está no cárcere sob a tutela estatal. (BERTONCINI, MARCONDES, 2or3, p. 7)
\end{abstract}

Como expresso nas colocações anteriores, a Constituição assegura a todos os cidadãos o direito a ter sua dignidade respeitada, mesmo que esteja inserida em locais punitivos do Estado, como as unidades prisionais. Cabe dizer, que o Estado tem sim a função de punir aqueles que não cumprem as leis vigentes, mas essa punição, deve se restringir a privação de liberdade ou medida análogas, sendo que submeter os detentos a situações degradantes não faz parte das funções do Estado, sendo um ataque direito aos direitos humanos e todas as garantias de cada cidadão brasileiro (SILVA, 2012)

$\mathrm{O}$ indivíduo que está preso, passa a ter sua tutela gerida pelo Estado, isso quer dizer que cabe ao poder público manter essa pessoa privada de liberdade como forma de punição, em contrapartida, também deve assegurar aos mesmos, plenas condições de dignidade, como colocá-lo em um ambiente com estrutura sanitária, alimentação, oferta de atendimento médico, assim como liberdade religiosa e apoio emocional e psicológico, visando sua reabilitação e futura reinserção em sociedade. Isso quer dizer que todos esses fundamentos, não são apenas um modo de seguir e respeitar a Constituição, mas também como uma estratégia de segurança pública, norteado pela ideia de que o respeito e estratégias de reabilitação da massa carcerária podem tornar a sociedade mais justa e os índices de criminalidade cada vez menores. 


\begin{abstract}
A dignidade da pessoa humana aparece no texto constitucional de 1988 no art. Io , inciso III, como fundamento da República Federativa do Brasil, configurando-se como um princípio norteador das políticas públicas. Tais políticas, portanto, devem ser elaboradas com observância ao referido princípio, uma vez que é o homem na configuração constitucional atual o centro e o fim da atividade estatal. A dignidade da pessoa humana por ser qualidade intrínseca a todas as pessoas pertence a todos, independentemente de sua raça, credo ou condição social, apresentando uma estreita ligação com o princípio da igualdade (BERTONCINI, MARCONDES, 2013, p. 8)
\end{abstract}

Como supracitado, a dignidade da pessoa humana precisa ser um elemento norteador de qualquer prática estatal. Com isso, o poder público precisa pensar estes aspectos de forma ampla, mesmo que por vezes vá na contramão de certas correntes de pensamento da opinião pública. Isso quer dizer que, embora muitos entendam e defendam que as penitenciárias devem realmente ofertar condições degradantes aos detentos como forma de punição aos atos cometidos pelos mesmos, discurso esse, endossado inclusive por lideranças políticas, é completamente inadequado e discrepante à Constituição brasileira (BERTONCINI, MARCONDES, 2013)

Ocorre que estes tipos de discursos, acabam fomentando as práticas negligentes do poder público em relação a melhoria das unidades penitenciárias brasileiras, que por receio de perca de popularidade, deixam de investir e pensar em estratégias voltadas a melhoria deste complexo cenário (BERTONCINI, MARCONDES, 2013)

Cabe salientar, que existem discussões dentro da sociedade, e que isso é completamente normal. Estratégias de segurança pública, meios para a diminuição de índices de criminalidade, e tantos outros assuntos próximos, devem e são discutidos em diferentes ambientes, desde o acadêmico até as discussões mais simples, de senso comum; isso jamais deve ser condenado. Porém, determinados elementos relacionados a dignidade e aos direitos humanos são imutáveis, sendo que "o núcleo básico dos direitos humanos é algo absoluto. São direitos universais imutáveis e que surgem da própria natureza humana" (SIQUEIRA, 2011, p. 258).

Sendo assim, fica claro através destas diferentes reflexões, que os direitos fundamentais e a dignidade da pessoa humana estão diretamente relacionadas, assim como o dever do Estado em assegurá-las para os cidadãos brasileiros, inclusive daqueles que estão inseridos dentro das unidades prisionais. 


\section{CONCEITO DE PENA E O PANORAMA ATUAL DAS PENITENCIÁRIAS BRASILEIRAS}

Antes de discorrer especificamente sobre o atual panorama em que se encontram as unidades prisionais brasileiras, é preciso discorrer brevemente sobre as funções das mesmas, elencando também quais as funções e a evolução histórica da aplicação da pena.

Deste modo, cabe embasar essa discussão a partir das reflexões de Gomes (2018). O pesquisador afirma que a aplicação e conceito de pena podem ser divididos em três grandes fases: a da vingança, a da punição divina e a vingança pública.

O primeiro período, classificado com a fase da pena em modo de vingança privada, tinha como característica reciprocidade dos atos, ou até mesmo trazer detrimentos maiores para quem cometeu o ato infracional primeiro. Isso quer dizer que, ao se efetivar um crime, o agente que o praticou poderia pagar com sua própria vida, ou na mesma proporção do ato que havia cometido. O chamado Código de Hamurabi é um exemplo claro da regra de reciprocidade ao ato ilícito:

\footnotetext{
O primeiro código de leis escrito de que se tem notícias, foi o Código de Hamurabi, que foi gravado em uma stela de basalto negro por volta do século XVIII a.C, que hoje se encontra no museu do Louvre, em Paris. O Código de Hamurabi defendia a vida e o direito de propriedade, e contemplava a honra, a dignidade, a família e a supremacia das leis em relação aos governantes. Esse código contém dispositivos que continuam aceitos até hoje, tais como a Teoria da imprevisão, que fundava-se no princípio de talião: olho por olho, dente por dente. Depois deste primeiro código, instituições sociais (religião e a democracia) contribuíram para humanizar os sistemas legais. (SILVA, 2012, p.2)
}

Essas normativas perduram por um período histórico, até ser substituída gradativamente pela chamada fase da punição divina. Gomes (2018) diz que a fase da punição divina, se caracterizou em um período que o Estado (poder do Estado) e a religião se confundiam, ou seja, ambos caminhavam juntos e exerciam influência um sobre o outro. No que se refere a caracterização da pena, o crime era tido como um pecado, e as punições se envolviam nos castigos divinos e da igreja, assim como de decisões do Estado ou do poder soberano. Com o aumento das sociedades e a busca por uma maior organização do Direito, as civilizações foram caminhando para um novo período, o da vingança pública.

Rousseau (2016) afirma que essa busca por uma harmonia social ocorre a partir do que o pensador chamava de "contrato social". Esse contrato, não se trata propriamente de um documento, mas sim, de uma ordem subjetiva que se estabelece 
dentro da sociedade, onde cada indivíduo assume e prática determinados atos em conformidade com a ideia de harmonia social, para que sua própria segurança, assim como da coletividade sejam assegurados. Mas para que isso se efetive, há necessidade de um poder moderador, que proporcione a tutela e tenha a obrigação e direito de punir transgressores.

Nessa conjuntura, se tem a punição pública, que é aquela feita pelo Estado, mas que não tem como foco a vingança, mas sim, a punição em conformidade com os direitos humanos. Se em alguns países a punição em proporções iguais ou maiores que o delito ainda ocorrem, a grande maioria das legislações não atuam desse modo, influenciadas especialmente por ideais da Revolução Francesa, o Estado deve punir, mas também dar condições de reabilitação e respeitar a dignidade de cada sujeito, independentemente dos atos que outrora tenham cometido (GOMES, 2018)

Hodiernamente, a legislação brasileira acolhe esse tipo de pensamento, (ao menos em âmbito legislativo) de que as cadeias e as ações do Estado devem ser reintegradoras e punitivas. Ou seja, ao ficar sob a tutela do Estado após um ato ilícito, um indivíduo deve receber como punição máxima a privação da liberdade, sem detrimentos a outros direitos basilares relacionados a sua dignidade, assim como devem ser oferecidas a este, condições para que sejam reabilitados e não voltem a cometer crimes após serem libertos (SIQUEIRA, 20II)

Contudo, a legislação vigente se mostra distante da realidade, pois as penitenciárias brasileiras são marcadas pela completa falta de estrutura, inadequadas condições sanitárias, ausência de estratégias de reabilitação, superlotação, entre outros aspectos negativo, como destacado:

\footnotetext{
O sistema prisional atual, ao invés de proporcionar a reabilitação do preso, acaba por criar novos infratores, mais violentos e revoltados com a sociedade. A falta de projetos de ressocialização para os detentos e a própria infraestrutura dos presídios torna o cárcere um ambiente vulnerável e propício à proliferação de doenças e epidemias e todo tipo de degradação humana, quando deveria oferecer as devidas assistências previstas na lei, que visa a garantia mínima dos Direitos Humanos. (MARQUES, et al., 2015, p.3)
}

Deste modo, se percebe que o Estado não vem cumprindo suas reais funções no que se refere ao tratamento de pessoas detidas por algum delito. Isso decorre de um 
processo histórico, além da ausência de medidas efetivas para o combate a esse cenário complexo. Ou seja, é preciso pensar as condições das unidades prisionais como uma questão de direitos humanos e de segurança pública, pois ao tratar de modo correto essa conjuntura, existe uma tendência de que os índices de criminalidade e reincidência sejam mitigados, impactando positivamente a sociedade em diversas frentes. Com isso, cabe na sequência do estudo, abordar algumas possíveis e importantes estratégias voltadas a reabilitação e futura ressocialização da massa carcerária.

\section{${ }_{4}$ ESTRATÉGIAS VOLTADAS A RESSOCIALIZAÇÃO}

Como supracitado, o Estado assume a tutela daqueles que são condenados pelo poder judiciário, com isso, o poder público priva estes da liberdade, os colocando em prisões. O objetivo deste processo é de que haja proteção da vida (das vítimas e possíveis futuras vítimas) assim como do patrimônio (público ou privado). Mas qual seria a lógica desta proteção, se após o cumprimento da pena, o indivíduo voltasse à sociedade e cometesse os mesmos atos ou atos ainda mais graves?

Sendo assim, é importante que as unidades prisionais sejam pensadas de modo amplo, como centros que punem através da privação de liberdade, mas também que tenham caráter pedagógico, capazes de fomentar ações que motivem e pacifiquem os detentos no sentido de reinserção social, cumprimento das normas vigentes e respeito à coletividade (BORBA, 2015)

Pensando nisso, é importante que existam estratégias voltadas a reabilitação e futura ressocialização do preso. Borba (2015) cita alguns importantes preceitos que devem ser pensados e seguidos para cumprir a Constituição e possibilitar a melhoria dentro das unidades prisionais e futura ressocialização: educação, segurança jurídica, acesso à saúde e possibilidades de inserção no mercado de trabalho.

A educação é uma ferramenta importante para a formação de qualquer sociedade, isso quer dizer que esse caminho é relevante para promover a igualdade social, assim como da conscientização e respeito as regras vigentes, a harmonia com a coletividade. No ambiente prisional, é possível resgatar essas etapas perdidas ou esquecidas por essa população. Incentivar a leitura, o conhecimento e aprendizagem em quaisquer níveis, desde o mais básico ao mais avançado, é uma forma de respeito 
aos detentos, assim como um depósito de confiança do Estado, dando a denotação de que todos podem ser reabilitados e reinseridos socialmente (BORBA, 2015)

Não há como pensar em educação ou em uma futura ideia de ressocialização, se não existir dentro do ambiente prisional adequadas condições sanitárias e atendimento médico quando se fizer necessário. É comum nesse tipo de ambiente existir disseminação de doenças, negligência nos atendimentos médicos, assim como falta de estrutura para tratamentos de doenças crônicas, que necessitam de acompanhamento médico e utilização de drogas de modo constante (MARQUES, et al., 2015)

A segurança jurídica também é outro aspecto extremamente relevante. Isso deve ocorre, obviamente, desde as fases de investigação, contudo, dentro do ambiente prisional também deve existir essa segurança. Um detento, entra no sistema prisional com uma pena previamente definida em juízo, sendo que sua privação de liberdade nunca deve ultrapassar esse limite. É importante que exista um acompanhamento jurídico em todo o processo, deste modo não se cria uma ideia de injustiça, ou de ineficácia do poder judiciário, se configurando também como algo relevante na busca da reabilitação e futura ressocialização (MARQUES, et al., 2015)

Muitos entram no submundo do crime impulsionado pela desigualdade social do país. A falta de estrutura para o acesso à educação, e a miséria de uma forma geral, acaba levando alguns a buscarem meios ilícitos para obterem o que desejam. A falta de oportunidades no mercado de trabalho é um destes fatores, principalmente para aqueles com passagens pelo sistema carcerário (BORBA, 2015)

Sendo assim, inserir cursos e ensinar ofícios de trabalho são relevantes estratégias para a futura ressocialização dos detentos em ambiente social. Se ao sair da prisão, essas pessoas encontrarem locais para trabalhar, as chances dos mesmos voltarem a cometer atos ilícitos é menor, pois podem vislumbrar a obtenção de um salário de forma digna, e consequentemente de ter estrutura para seguir inseridos em sociedade sem praticar novamente nenhum crime (MARQUES, et al., 2015)

Ou seja, as estratégias voltadas a ressocialização são se resumem a ações isoladas, é preciso que a questão seja pensada de forma ampla, com metodologias estruturadas de curto, médio e longo prazo. Somente assim se pode vislumbrar um 
futuro com menores índices criminais, com unidades prisionais sem superlotação e consequentemente, com maior harmonia social.

\title{
5 METODOLOGIA
}

Para alcançar os objetivos propostos, a presente pesquisa teve como encaminhamento metodológico uma revisão de literatura, em estudos atrelados a atual situação das penitenciárias brasileiras, assim como de documentos e pesquisas relacionadas aos preceitos constitucionais dos direitos humanos e da dignidade da pessoa humana.

Acerca da importância da atenção e escolha correta do encaminhamento metodológico, é relevante colocar que:

\begin{abstract}
A Metodologia Científica significa estudo dos métodos ou da forma, ou dos instrumentos necessários para a construção de uma pesquisa científica; é uma disciplina a serviço da Ciência. Metodologia é a parte onde será indicado o tipo de pesquisa que será empregado, as etapas a serem realizadas. O conhecimento dos métodos que auxiliam na elaboração do trabalho científico. (OLIVEIRA, 2013, p.4)
\end{abstract}

Destacado a relevância de uma adequada metodologia ao tipo de pesquisa, cabe também trazer as definições e reflexões de Severino (20II) acerca da pauta:

[...] um instrumental extremamente útil e seguro para a gestação de uma postura amadurecida frente aos problemas científicos, políticos e filosóficos que nossa educação universitária enfrenta. [...] São instrumentos operacionais, sejam eles técnicos ou lógicos, mediante os quais os estudantes podem conseguir maior aprofundamento na ciência, nas artes ou na filosofia, o que, afinal, é o objetivo intrínseco do ensino e da aprendizagem universitária (SEVERINO, 20II, p. 18)

A presente pesquisa, como supramencionado se trata de uma revisão de literatura, que segundo Severino (2011), se refere a uma discussão a partir de inúmeras pesquisas, objetivando compreender os entendimentos já adquiridos, e deliberando também a partir da contraposição de reflexões, com a ideia de brotar um conhecimento novo e importante academicamente e a nível social.

Os elementos trazidos por meio da revisão de literatura serão tratados de modo qualitativo, ou seja, buscando uma análise e conclusões mais subjetivas acerca do tema, sem definições pragmáticas acerca da pauta do estudo. Os estudos considerados na presente revisão de literatura são aqueles publicados entre os anos de 2011 a 202I, colhidos em sites e portais acadêmicos renomados. 


\section{RESULTADOS E DISCUSSÃO}

A partir da exposição de diferentes reflexões acerca da situação das prisões no Brasil, se tornou relevante também abordar alguns aspectos basilares acerca dos chamados direitos fundamentais. Os direitos fundamentais se referem a determinadas regras presentes na Constituição e que tem importância cabal, como exemplo destes direitos, é possível citar o acesso a tratamento de saúde sem custos, bancados pelo Estado, acesso a educação, moradia, alimentação, segurança, entre outros. Todos esses aspectos, segundo os pesquisadores consultados para a pesquisa, se relacionam diretamente a dignidade, que é um elemento central e norteador de qualquer ação dentro da sociedade.

Sendo assim, a dignidade da pessoa humana deve nortear todas as ações do poder público em relação aos cidadãos e também as instituições geridas pelo governo. Dentre estas, estão às unidades prisionais, que servem como ferramentas para o cumprimento de premissas constitucionais, a citar, a privação de liberdade como forma de punição e afastamento de possíveis transgressores da lei de novas vítimas, ou de patrimônio alheio, seja este público ou privado.

Como dito, o dever de julgar, condenar e punir alguém é obrigação do Estado. Mas essa obrigação e conjuntura vistam hodiernamente, advém de um longo processo histórico. Se antes, o conceito de pena estava diretamente atrelado a vingança, a citar o Código de Hamurabi, pautado na reciprocidade dos atos, a também chamada Lei de Talião, houve mudanças nessas concepções ao longo do tempo.

Embora os atos devessem ser recíprocos, se mostravam desproporcionais e também inadequados do ponto de vista restaurativo, sendo que a vingança era o argumento central para esse tipo de ação, desconsiderando os possíveis efeitos em cadeia que esses tipos de procedimentos poderiam causar. Posteriormente, o conceito de pena passa a adquirir novas faces, onde o Estado e a igreja se tornam instituições completamente ligadas e misturadas, ou não se sabia ao certo a função exata de cada uma, consequentemente, gerando influência uma sobre as outras.

Com a evolução das sociedades, e após algumas revoluções e inserção de ideologias de diferentes faces, houve uma ruptura dessa chamada vingança divina ou 
punição divina. Se formata-se assim, uma nova concepção do conceito de pena, a chamada punição pública.

Rousseau (2016) afirma que essa mudança social é uma evolução das civilizações, impulsionadas pelo que o pensador chamava de "contrato social". Afirma ainda que isso decorre a partir de uma séria de prerrogativas que se inserem no imaginário popular, com teor subjetivo, isso quer dizer que não existe propriamente ou necessariamente uma legislação específica, e sim, um hábito comum a todos. Diz também que essa evolução decorre de um processo natural, como uma forma de autoproteção dos indivíduos, que buscam através de um poder moderador a tutela e também a segurança a partir de relações mais estáveis e harmoniosas.

Logo, se ingressa na discussão acerca das circunstâncias nas quais as prisões estão no Brasil. Se percebe que as unidades estão sendo insuficiente em diversos aspectos, como nas condições sanitárias, de atendimento médico, de oferta de educação, com a superlotação, além da ausência de medidas efetivas para a reabilitação e posterior reinserção destas pessoas em sociedade.

Em relação as estratégias para a reabilitação, foi possível destacar no estudo os seguintes aspectos: educação, segurança jurídica, acesso à saúde e possibilidades de inserção no mercado de trabalho. Todos esses elementos são extremamente condizentes com os preceitos básicos da Constituição, efetivando, consequentemente, a dignidade em relação as pessoas inseridas no ambiente prisional.

Por fim, cabe salientar que a efetivação dos elementos promulgados na Constituição dentro das unidades prisionais, requer uma série de iniciativas estatais, voltadas a uma reforma das cadeias, tratando as mesmas como ambientes de punição, mas acima de tudo, como locais capazes de mudar o panorama de vida destas pessoas, incentivando que as ações fora da lei não voltem a se repetir.

\section{CONCLUSÃO}

A problemática norteadora do estudo se referiu as condições degradantes da população carcerária, e se isso é fator determinante para os elevados índices de reincidência criminal no Brasil, e a partir da deliberação de diferentes autores, foi possível evidenciar a veracidade desta afirmação. A hipótese levantada de que a ausência de políticas públicas de reestruturação das penitenciárias é algo determinante 
para a não efetivação de preceitos constitucionais, foi confirmada, na medida em que os pesquisadores consultados, afirmam que não se percebe no Brasil, ao longo de muitas décadas, iniciativas efetivas voltadas para este fim, culminando em uma situação cada vez mais degradante dentro das cadeias.

O estudo teve como objetivo analisar de quais modos os direitos fundamentais da população carcerária são violados. E a partir da revisão de literatura trazida, foi possível evidenciar diversas ocasiões em que as prerrogativas constituições, como a dignidade e os direitos humanos são violados em relação aos detentos, desde a superlotação das cadeias, que se caracteriza como um elemento direito e concreto, assim como de aspectos mais subjetivos, como a ausência de políticas públicas voltadas a reabilitação dos detentos.

A Constituição trata de várias formas a importância da preservação dos Direitos Humanos de todos os cidadãos do país, independentemente da situação ao qual o mesmo se encontre. Deste modo, não se permite que a população carcerária seja punida em desconformidade com a lei, sendo que a punição deve se resumir somente a privação de liberdade, e jamais com detrimentos a dignidade destas pessoas.

Outro ponto destacado na pesquisa, e que merece menção nas reflexões finais do estudo, dizem respeito a evolução do conceito de pena ao longo da história. Em síntese, esses conceitos podem ser divididos em três grandes fases: da vingança privada, da punição divina e da punição pública, que a forma na qual a legislação brasileira trabalha hodiernamente.

Cabe dizer, que não somente a função punitiva através da privação de liberdade é responsabilidade do Estado, julgar, investigar e proporcionar condições para a redenção do detento após o cumprimento da pena são elementos igualmente inerentes as ações e deveres do poder público.

Deste modo, cabe enfatizar que os objetivos da presente pesquisa foram alcançados, sendo que os principais conceitos acerca dos direitos fundamentais e da dignidade da pessoa humana foram trazidos. Também foi mostrado aspectos relevantes acerca da evolução do conceito de pena, assim como uma breve discussão acerca da construção dos entendimentos brasileiros atuais, utilizando como referência abordagens e reflexões de Rousseau, sintetizadas pelo o que o pensador chamou de "contrato social". 
Deste modo, se entende a reestruturação completa das unidades prisionais como algo urgente do ponto de vista constitucional e também de segurança pública e melhoria em relação a harmonia social, devendo Estado e comunidade trabalhar em conjunto para a efetivação deste cenário.

\section{REFERENCIAS}

BERTONCINI, Mateus Eduardo Siqueira Nunes. MARCONDES, Thais Caroline Anyzewski. A dignidade da pessoa humana e os direitos humanos no sistema prisional brasileiro. Portal Publicadireito, 2013. Disponível em: <

http://www.publicadireito.com.br/artigos/?cod=ecio93fer626f $25 \mathrm{~b}>$ Acesso em: $28 \mathrm{de}$ março de 202I

BORBA, Dandrea Moura. Reintegração social: estratégias de intervenção junto aos encarcerados. Portal Susepe, 2015. Disponível em: < http://www.susepe.rs.gov.br/upload/1326887807_Reintegracao\%2oSocial.pdf > Acesso em: 28 de março de 202I

GOMES, Luís Fernando. A aplicação da Constituição dentro das cadeias, Portal Publicadireito v. 16, n. 52, p. 52-68, ago./dez. 201852

MARQUES, Josiane. Et. al. A realidade do sistema prisional no brasil: um dilema entre as penas e os direitos humanos. V Seminário da Pós Graduação em Ciências Sociais: Cultura, Desigualdade e Desenvolvimento - realizado entre os dias 02, 03 e 04 de dezembro de 2015, em Cachoeira, BA, Brasil

OLIVEIRA, Tamires. A importância da metodologia científica para o ensino e aprendizagem no ensino superior. Educere, Congresso Nacional de Educação, Curitiba, 2013

ROUSSEAU, Jean Jacques. Do Contrato Social. Rio de Janeiro: Nova Fronteira, 2016.

SEVERINO, Antônio Joaquim. Metodologia do trabalho científico. $29^{\underline{a}}$ ed. São Paulo: Cortez, 2011.

SILVA, Flavia Martins André da. Direitos fundamentais. Rio de Janeiro: Top Books, 2012

SIQUEIRA JR., Paulo Hamilton. A dignidade da pessoa humana no contexto da pós-modernidade: o direito no século XXI é tolerância, bom senso e cidadania. In: 